\title{
EL LENGUAJE DE LA CAUSALIDAD \\ DE NUESTRAS ACCIONES: HACIA UNA RESIGNIFICACIÓN DEL DOMINUS EN TOMÁS DE AQUINO
}

\author{
SANTIAGO ARGÜELLO \\ CONICET (Argentina)
}

\begin{abstract}
RESUMEN: Este trabajo consiste en un estudio de la teoría del dominio, en el que se muestran algunos aspectos de la recepción que la obra de Tomás de Aquino registra de la filosofía de Aristóteles al respecto. Para llevar a cabo el análisis, se ha escogido como punto de partida la interpretación efectuada por Hannah Arendt -recogida luego por Jürgen Habermas -, según la cual ya en el Aquinate habría comenzado a abandonarse una filosofía genuinamente política del dominio en beneficio de una de carácter estrictamente social; inicio, por lo demás, de un proceso que culminaría en el posterior auge en la Edad Moderna de la primacía de lo social y lo privado por encima de lo político y lo público. A fin de determinar la validez de este esquema hermenéutico - no carente, por cierto, de divulgación-, en primer lugar se realiza aquí un examen lingüístico de la enseñanza aristotélica y tomística sobre la realidad del dominio. Al respecto, se observa ante todo un carácter altamente analógico en la familia conceptual del término «dominio", al tiempo que es posible concluir que no existe beligerancia alguna entre lo social y lo político, ni en Aristóteles, ni en Tomás de Aquino. El extravío hermenéutico arendtiano se revela finalmente al considerar la orientación fundamental de la doctrina aristotélica y tomística del dominio, a saber, su servicio a la dimensión ultrapolítica de la actividad más propiamente humana, que es la del noûs (mens).
\end{abstract}

PALABRAS CLAVE: dominio, poder, Tomás de Aquino, Aristóteles

\section{The Language of Causality by Human Actions: Redefining dominus in Thomas Aquinas}

\begin{abstract}
The present paper deals with the theory of Dominion/Dominium, trying to show some aspects of Aquinas' interpretation on the works of Aristotle. To begin with, we discuss with Hannah Arendt's understanding of the issue - resumed again by Jürgen Habermas-. According to it, Aquinas would be who have initiated a philosophy properly social of dominium at the expense of the political theory on it held by Aristotle. In order to evaluate the strength or weakness present in Arendt's point of view, we first bring about a linguistic analysis on how some Aristotle's and Aquinas's texts use the term dominium (arjé), and others closely related to it. Departing from the highly analogical feature in that term, then we conclude in the absence of any antagonism between «the social» and «the political» within the Thomistic or Aristotelian philosophy of Dominion/Dominium. The falsity of Arendt's exegesis is finally revealed in detecting its disagreement with the main direction of the Thomistic and Aristotelian theory of dominium, namely, that the most properly human activity -that of noûs (mens) - is above any ethical dimension of human power.
\end{abstract}

KEY WORDS: Dominion/Dominium, Power, Thomas Aquinas, Aristotle.

\section{INTRODUCCIÓN}

El actual desacuerdo acerca de lo que significa «dominio»(dominium) en Tomás de Aquino, podría llevar a revisar la validez de ciertos presupuestos 
hermenéuticos que acaso se consideran inconmovibles. Por ejemplo, Hannah Arendt y Jürgen Habermas (quien de alguna forma depende en este caso de la anterior $)^{1}$ conciben que cuando el Aquinate habla de dominio político, en realidad está hablando reductivamente de dominio económico o, lo que es prácticamente igual para ellos, de dominio monárquico. El argumento de ellos es este: el rex o princeps gobierna o «domina monárquicamente» el pueblo del reino, de modo semejante a como el paterfamilias, en tanto que dominus, gobierna la familia de su casa. Ambos lo hacen, más que de manera a-política, de manera infra-politica; es decir, de modo social. Conclusión: Tomás de Aquino ha operado la extensión del modus del dominio doméstico a la entera realidad social ${ }^{2}$. Cuál sea la debilidad de los presupuestos de esta interpretación, es lo que a continuación examinaré, tratando de despejar las dificultades para que aparezcan los rasgos originales de la doctrina tomística.

\section{ARendt y la Reductiva dimensión social del dominus en Tomás de Aquino}

En el cap. II de The Human Condition, la filósofa alemana sostiene que, comparado con el pensamiento griego (Aristóteles sobre todo), en Tomás de Aquino se da una «inconsciente sustitución de lo social por lo político»³ es decir, una comprensión reductiva del carácter comunitario del hombre a sus necesidades biológicas. En cambio, prosigue Arendt, «según el pensamiento griego, la capacidad del hombre para la organización política no es sólo diferente, sino que se halla en directa oposición a la asociación natural cuyo centro es el hogar (oikía) y la familia ${ }^{4}$. El punto de partida de la interpretación de Arendt es claro: la supuesta oposición entre naturaleza social y artificio político. A tal punto es así que, según esta autora, no sólo fue opinión de Aristóteles sino incluso un hecho, que la formación de la polis griega requirió la destrucción de la familia como institución ${ }^{5}$. De este modo, Arendt pretende ubicar a Aristóteles como

1 Véase Arendt (2003: 37-95, es decir, el entero cap. II); Habermas (1987: 54-57). La dependencia de este último respecto de la primera puede observarse, v.g., por Habermas (1987: 50, n. 4 y 56, n. 17).

2 Cfr. Habermas (1987: 55-56).

3 ARENDT (2003: 38).

4 AREndt (2003: 39).

5 Cfr. Arendt (2003: 39). Es notable al respecto cómo Arendt pasa por alto un pasaje al inicio de la Política (I, 2, 1253a1-8) en el que, citando a Homero, Aristóteles establece expresamente la necesidad de la familia como constitutivo irremplazable para la politicidad: el politikòn zôon no es para Aristóteles -ni para Homero- un hombre sin hogar (ánestios), es decir, un homeless. Arendt parece perder de vista que, como allí mismo afirma Aristóteles, la polis no es puro artificio, sino «una de las cosas naturales (tôn phýsei)», y como tal, tiene base en la familia, la primera y más natural de las asociaciones humanas. 
abanderado de lo político, y a Tomás de Aquino de lo social ${ }^{6}$. Como veremos, esta oposición, al menos como las conciben Arendt y Habermas, es inexistente.

El pasaje quizá más clarividente de la exposición arendtiana al respecto es el siguiente:

«El profundo malentendido que expresa la traducción latina de "político" como "social", donde quizá se ve más claro es en el párrafo que santo Tomás dedica a comparar la naturaleza del gobierno familiar con el político; a su entender, el cabeza de familia tiene cierta similitud con el principal del reino, si bien, añade, su poder no es tan "perfecto" como el del rey (Santo Tomás, Summa theologiae, II-II, q.50, a.3 [ad 3])» ${ }^{7}$.

La breve glosa del texto es correcta, pero la deducción que Arendt hace del mismo, no lo es. Luego explicaré por qué esta intérprete no entiende la analogía tomista entre paterfamilias y rex. De momento notemos que para Arendt el contrapunto de esa analogía establecida por Tomás de Aquino es la supuesta oposición establecida por Aristóteles entre «el gobierno despótico de un único hombre (mon-archia) propio de la organización doméstica» y «la organización completamente diferente de la polis ${ }^{8}$. Ciertamente, existen textos de Aristóteles que se expresan en términos similares:

«No es lo mismo el poder del amo (despoteía) y el político (politiké), ni todos los poderes (arjaí) son idénticos entre sí, como algunos dicen; pues uno se ejerce sobre personas libres por naturaleza, y otro, sobre esclavos, y el gobierno doméstico (oikonomikè) es una monarquía (monarjía) (ya que toda casa es gobernada por uno solo), mientras que el gobierno político es sobre hombres libres e iguales» ${ }^{9}$.

Sin embargo, los modos de gobernar o dominar que en Aristóteles son sólo distintos, para Arendt resultan incluso antagónicamente opuestos. El matiz no es de poca monta. Para empezar, además de no existir antagonismo entre los poderes aludidos, el gobierno doméstico no es para el Estagirita únicamente de tipo despótico y monárquico, sino también político y aristocrático. En efecto, el que gobierna la casa no es únicamente alguien que manda sobre esclavos o seres imperfectamente libres, como los niños ${ }^{10}$, sino también sobre un ser per-

6 «Tomás de Aquino ya no entiende esta comunidad [ciudadana] de una forma genuinamente política: la civitas se ha convertido subrepticiamente en societas». (HABERMAS, 1987: 55; cfr. 56). La consecuencia de esto es que, supuestamente, «Tomás de Aquino transforma la política aristotélica en una filosofía de lo social» (ibid.).

ARENDT (2003: 41).

8 AREndt (2003: 86, nota n. 15: he modificado la traducción de este fragmento ateniéndome a la versión original). Nótese, por lo demás, que Arendt alude allí a los Económicos que no son sino del Pseudo Aristóteles. En esa obra se lee: «el arte de gobernar una ciudad depende de muchos jefes, el arte de gobernar una casa de uno solo (politikè ek pollôn arjónton estín, he oikonomikè dè monarjía)». Ps.-Aristóteles, Económicos, 1343a3-4.

9 Pol. I, 7, 1255b16-22. "La polis es una comunidad de hombres libres (eleuthéron)». Pol., III, 6, 1279a21-22.

10 Cfr., por ej., Pol., III, 1, 1275a14-18; 4, 1278a4-6. 
fectamente libre, como la mujer ${ }^{11}$. Por otro lado, de la distinción entre el modo de gobernar a los esclavos y a los niños se evidencia que ni siquiera para Aristóteles significan lo mismo «despótico» $\mathrm{y}$ "monárquico ${ }^{12}$ : no toda monarquía es de carácter despótica; la realeza despótica se llama tiranía, y es una corrupción de la verdadera monarquía. Valga acotar a este respecto que en Aristóteles no existe un único término que designe al señor de la casa englobando de una vez por todas, genéricamente, cada una de las relaciones domésticas mantenidas por él. Y en Tomás de Aquino, aunque «dominium» sea el término que engloba genéricamente todos los modos de gobierno existentes -incluso los que se ubican fuera de la casa-, no parece que él aplique invariablemente con el mismo rigor genérico el término «dominus» a todo tipo de gobernante ${ }^{13}$.

En síntesis, la oposición establecida por la hermenéutica arendtiana es clara: de un lado, lo social, lo familiar, lo privado, lo natural, lo monárquico, lo jerárquico y desigual, lo constituido por la necesidad y hasta la violencia propio de un despotismo que manda y ordena; y, por último, lo irracional o, por lo menos, lo infrarracional e inexpresivo. Todo esto estaría representado por el animal sociale, cuya figura más sobresaliente es, según Arendt, el dominus medieval; el cual, si no elaborado directamente por Tomás de Aquino, al menos sí se encontraría fielmente reflejado en su teoría política. Del otro lado de la oposición, lo político, lo público, lo común, lo artificial o artístico, lo poliárquico, lo igual, lo constituido por la libertad y casi como tentado de anarquismo ${ }^{14}$; y por último, lo racional y expresivo, según la lógica de una palabra sugerente y persuasiva. Todo esto estaría representado por el zôon politikón que, surgiendo ya en el héroe homérico - «agente de grandes acciones y orador de grandes palabras» ${ }^{15}$ - , se despliega luego en tantas otras figuras de la historia, la literatura y la filosofía helénicas, hasta alcanzar en Aristóteles su formulación más acabada. Por lo demás, conforme a la misma lógica arendtiana, todas estas

11 «El gobierno del marido sobre la mujer es, evidentemente, aristocrático (aristokratikè), pues el marido manda (árjei) de acuerdo con su dignidad (axían), en lo que debe mandar, y asigna a su mujer no más que lo que se ajusta a ella». EN, VIII, 10, 1160b33-35.

12 Cfr., por ej., EN, VIII, 10, 1160b24-32.

13 En algún caso Tomás restringe el dominus a la relación de tipo despótica: «tres sint partes yconomice, id est gubernatiue domus, secundum tres coniugationes predictas, de una earum iam dictum est, scilicet de despotica que pertinet ad dominum et seruum; unde restat dicendum de secunda que est paterna pertinens ad patrem et filium, et de tertia que est nuptialis pertinens ad uirum et uxorem». (Thomas de Aquino (1971: 113), In Pol., I, c.10, lin. 21-28). Naturalmente, dicha restricción no es invariable: «etiam ille qui habet officium gubernandi et dirigendi liberos, dominus dici potest» (Thomas de Aquino (1889: 429), S.th., I, q.96, a.4; cfr. I, q.92, a.1, ad 2). Por lo demás, la imposibilidad de que en Tomás de Aquino el término dominus quede restringido al ámbito de lo despótico se evidencia porque, si así sucediera, las relación del Señor (Dominus) para con sus creaturas resultaría invariablemente despótica.

14 «Ser libre significaba (...) ni gobernar ni ser gobernado». ARENDT (2003: 44). Precisamente lo contrario a lo que piensa Aristóteles: ver, por ej., Pol., III, 4.

15 La frase es de Ilíada, IX, lin. 443, y se refiere concretamente a Aquiles: ver ARENDT (2003: 39). 
características opuestas decantarían luego, en la época moderna, en la conformación de lo nacional como opuesto a lo republicano ${ }^{16}$.

A decir verdad, ni existe tal falta de carácter natural y familiar en la concepción política de Aristóteles, ni una análoga carencia tal de politicidad en la concepción social de Tomás de Aquino ${ }^{17}$. Con todo, sí es verdad que en Aristóteles se observa una orientación de lo familiar a lo político. Ahora bien, ¿se opera en el Aquinate, como pretende Arendt, una reducción u orientación de lo político a lo familiar?

\section{EL DOMINIO COMO TIPO O ESPECIE DE PODER: SUS ESFERAS Y LA RELACIÓN ANALÓGICA ENTRE ELLAS}

La analogía entre el ámbito político y el psicológico constituyen en Aristóteles y Tomás un ejercicio de comprensión constante y de alcance omniabarcativo; en efecto, la analogía recorre en ellos, de principio a fin, tanto la entera materia sociopolítica cuanto la entera materia antropológico-ética, de tal modo que cada elemento de la teoría política encuentra algún reflejo en la antropológico-ética, y viceversa.

Ahora bien, los términos compartidos por la filosofía política y la antropología, son - para estos autores - términos originalmente políticos, esto es, pertenecientes a un ámbito más manifiesto, amplio y exterior, transfiriéndose luego desde allí a ámbitos más interiores y restringidos de la estructura de la acción humana. En efecto, «la virtud de la parte (mérous aretén) debe examinarse (blépein) en relación con (prós) la virtud del todo (hólou aretén)» ${ }^{18}$. Esto es algo

16 Al respecto puede verse ArendT (2003), acápite 5 ( La polis y la familia») del cap. II, esp. la nota n. 14, que dice así: «no pretendo negar que la nación-estado y su sociedad surjan del reino medieval y del feudalismo, en cuyo marco la unidad familiar y el conjunto de vasallos tienen una importancia inigualable en la antigüedad clásica».

17 En Bertelloni y CRESPo (2013) también se encuentra una crítica a la interpretación de Arendt que estamos examinando, pero 1) se hace únicamente en referencia a Aristóteles, no a Tomás de Aquino; 2) la crítica se refiere al error en que cae Arendt por separar domesticidad de politicidad, esto es, por despolitizar o pre-moralizar lo doméstico. Dicho de otra forma, Bertelloni y Crespo parecen concordar con Arendt en que lo doméstico no tendría valor por sí mismo, concluyendo que, del hecho de que lo doméstico no sea una realidad pre-moral, se seguiría que tampoco tuviera valor pre-político. Es decir, para Bertelloni y Crespo lo económico tiene cierta realidad en sí, pero sólo tiene valor en lo político. La inconveniencia de esta interpretación es que, como es evidente, se despoja a la realidad doméstica o económica de valor específico propio; algo que parece tener no sólo según Tomás de Aquino, sino también según el mismo Aristóteles. A mi modo de ver, si bien es preciso afirmar con Aristóteles la esencial apertura y orientación teleológico-perfectiva de lo económico a lo político, no obstante sigue habiendo distinción axiológica o ética específica entre ambos órdenes, no resultando totalmente subsumido uno en el otro.

18 Para la transferencia de las clases de régimen del ámbito político al familiar, puede verse EN, VIII, 10; y del ámbito político al personal —o antropológico, si se quiere; en lo cual se incluye una reflexión sobre la vida animal—, puede verse Pol., I, 5. Al respecto, cuando en 
particularmente visible si el análisis se restringe al concepto de dominio. De este modo, para entender en qué consiste y qué implica que seamos domini actus nostri ${ }^{19}$, dueños de nuestros propios actos, conviene atender primero a las implicancias de que un hombre sea señor respecto de algo distinto de sí, es decir, dueño de algo y/o de alguien.

Tal como expresa Tomás en diferentes lugares, el dominio (dominium o dominatio) es una relación fundada en el poder ${ }^{20}$. Definirlo de esa manera es hacerlo de modo trascendental, diferenciándose así del modo en que aparece en los salmantinos - Vitoria, Soto y el resto-, para quienes el dominio viene a ser una facultad de uso según la ley ${ }^{21}$, resucitando de algún modo el sentido de la doctrina en el Derecho Romano ${ }^{22}$. Ahora bien, Aristóteles ya había aludido a este poder originario (arjé), refiriéndose a él como poder para gobernar y ser gobernado en sentido genérico (dýnasthai árjein kaì árjesthai: Pol., III, 4; 1277a2623); es decir, como una relación entre mandar, predominar, presidir

Thomas de Aquino (1889: 427), S.th., I, q.96, a.2, se lee que «en el hombre se encuentran de algún modo todas las cosas: y por eso, le compete dominar a otras realidades (aliis) según el modo con el que domina a aquellas realidades que se encuentran en él mismo», es preciso entender que desde el dominio presente en la realidad humana se entiende el dominio respecto a otras realidades no humanas, como los animales, las plantas y seres inanimados; ese «aliis» no significa «a otros hombres». En este sentido, si bien el texto entiende «homo» de forma individual, no sería inadecuado extender su alcance a su ser comunitario. Con todo, existe cierta diferencia al respecto entre Aristóteles y Tomás: aunque en ambos la analogía del dominio comience en la esfera comunitaria, sin embargo, Tomás de Aquino parece sentir mayor libertad para prescindir de dicha esfera. En efecto, si bien en el griego la realización del hombre es concebida de forma transpolítica, no obstante sigue fuertemente atada o ligada a la comunidad política; en el medieval, en cambio, la forma suprapolítica de realización personal, resulta mucho más marcada.

19 «Non enim per passionem nostri actus domini sumus sed per solam rationem». Thomas de Aquino (1965a: 20), Super Iob, c.3, lin. 33-35.

20 Cfr. Q. de pot., q.7, a.10, ad 4; S.th., I, q.13, a.7, ad 1; C.G., II, c. 12.

21 No en vano, «dominio y propiedad son dos términos utilizados normalmente por los autores de la Segunda Escolástica como sinónimos» (LóPEZ, 2008: 82). Así, en el tratado de iustitia Vitoria define el dominio como "facultatem quamdam ad utendum re aliqua secundum jura» (q. 62, a. 1), cit. por LóPEz (2008: 82; cfr. ibíd., 78), que sigue la siguiente ed.: Francisco de Vitoria, Comentarios a la Secunda Secundae, Beltrán de Heredia, V. (ed.), Biblioteca de Teólogos españoles, Madrid - Salamanca, 1932-1954. Y Domingo de Soto (1559: 202), De iustitia et iure, IV, q.1, a.1, se expresa en términos similares: "dominium ergo, si secundum artem describes, est propria cuiusque facultas et ius in rem quamlibet, quam in suum ipsius commodum usurpare potest quocunque usu lege permisso»; cfr. López (2008: 82-83).

22 «Para Vitoria, y de acuerdo con las Instituciones de Justiniano, el tema del dominio se inserta en la discusión sobre la justicia conmutativa (iustitia commutativa)»(Tellkamp, 2009: 41; cfr. 42). Es significativa la sentencia de Aubert (1955: 71, n. 2), siguiendo a Spicq: el sentido que Tomás aplica al término dominium «n'est pas celui du droit romain».

${ }_{23}$ Que se trata de una capacidad general se comprueba por la especificación de esa capacidad que Aristóteles presenta inmediatamente a continuación de la frase citada: «y la virtud de un ciudadano digno parece que es el ser capaz de mandar y de obedecer bien (kalôs)». (Pol., III, 4; 1277a27-28). De forma similar se había expresado en el libro primero: «hay muchas formas de mandar y de obedecer (eíde pollà kaì arjónton kaì arjoménon éstin), 
respecto de otro, y obedecer a ese que manda o preside, a lo que el mismo Aristóteles designa como "una obra en común»: "dondequiera que uno manda y otro obedece, hay una obra propia de ambos (hópou dè tò mèn árjei tò d'árjetai, ésti ti toúton érgon)»(Pol., I, 5, 1254a28). Esta realidad común -la del dominio-, según Aristóteles es susceptible a su vez de ser aplicada a realidades no sólo del orden político, sino también de otros órdenes, por analogía: «En efecto, en todo lo que consta de varios elementos y llega a ser una unidad común (gínetai hén ti koinón), ya de elementos continuos o separados, aparecen siempre el dominante y el dominado (tò árjon kaì tò arjómenon), y eso ocurre en los seres animados (tô̂s empsýjois) en cuanto pertenecen al conjunto de la naturaleza» (Pol., I, 5, 1254a29-32). El jefe aristotélico es fundamentalmente un árjon, y el súbdito un arjómenon. Ahora bien, con el solo uso de estos términos, la relación de domino todavía no queda calificada de buena o mala, de mejor o peor (ver nota n. 23), o especificada como despótica, política o regia ${ }^{24}$. A diferencia de la autarquía propia de la realidad divina, que trasciende todo gobierno ${ }^{25}, \mathrm{y}$ por tanto no necesita mandar sobre nada ni nadie (y mucho menos obedecer), la realidad humana está transida en su totalidad —en todas sus capas- por la relación de gobernante-gobernado. La adhesión por parte de Tomás de Aquino a esta concepción de la condición intrínsecamente política de la naturaleza humana, se nota por su incondicional preferencia en este punto por Aristóteles ${ }^{26}$, cuya doctrina, sin embargo, reelabora de forma original ${ }^{27}$.

En el Libro I de la Política, Aristóteles ha elaborado su propia traducción o concreción de esta realidad relativa estructural para el hombre que en latín se

y siempre es mejor (beltion) el mando sobre subordinados mejores (tôn beltiónon)». Pol., I, $5,1254 \mathrm{a} 24-25$.

24 «Despotikèn arjèn kaì politikén (...) è basilikén». Pol., I, 5, 1254b4-5.

25 Cfr., por ej., Pol., I, 2, 1253a4.

26 Cfr. Thomas de Aouino (1889: 429-430), S.th., I, q.96, a.4. Bertelloni (2009: 21) ha sabido poner de relieve que Tomás fue el primer autor medieval en ofrecer una «reflexión sistemática y sólida acerca de la "politica" [en sentido aristotélico] que logró fundamentar teóricamente el uso del vocablo en el nuevo discurso filosófico de la philosophia practica». Con todo, al mismo tiempo él aduce que «Tomás se distancia de Aristóteles cuando introduce la sociabilidad como antecedente inmediato de la politicidad» (ibid.: 29; cfr. ibíd., 37). Tal como venimos argumentando, no sería, a nuestro juicio, en este punto que Tomás se aparta de Aristóteles. Desde luego, como apunto en la nota siguiente, considero que el Aquinate progresó o avanzó respecto de la filosofía política aristotélica, pero jamás apartándose de los principios de esta.

27 La originalidad de la concepción del dominio por parte del Aquinate respecto de Aristóteles es susceptible de ser observada en más de un punto. Para decirlo en pocas palabras, la filosofía tomista, a la par que desprende al hombre de la realidad humana del dominio, elevándolo por encima de esta, consigue elevar la realidad del dominio hasta situarla en Dios - de esa forma, el dominio resulta resignificado. Junto a ello, la reanudación de la teoría política aristotélica por parte de Tomás de Aquino, antes que depreciar en él la tradición del pensamiento agustiniano al respecto, contribuye a su potenciación. El hecho de que Thomas de Aquino (1889: 429-430), S.th., I, q.96, a.4 concluya citando el De civitate Dei, no parece azaroso. 
tradujo como «dominium»: según el canon aristotélico, las distintas formas de dominio son la relación heril o despótica (arjé despotiké), la relación procreadora y paterna (arjé teknopoietiké, patriké), la relación conyugal (arjé gamiké), la relación política (arjé politiké) y la relación regia o monárquica (arjé basiliké) ${ }^{28}$. De estas, las tres primeras pertenecen genéricamente a la administración doméstica, económica o familiar, y se distinguen entre sí primariamente en razón de que el esclavo, y por extensión los animales domésticos y las demás cosas útiles con los que el señor de una casa se relaciona, no son seres libres, al contrario de su mujer y sus hijos, que sí lo son. Ahora bien, el gobierno de la mujer y el de los hijos no es del mismo tipo (trópos), pues a los hijos corresponde gobernarlos de manera regia (basilikôs) y a la mujer de manera política (politikôs) ${ }^{29}$ y aristocrática (aristokratikè) ${ }^{30}$.

De esta manera, lo primero a hacer notar es que, en contra de lo que opina Arendt, no existe para Aristóteles una división tajante entre la forma de gobernar en el ámbito familiar y en el ámbito político: las posibles variaciones en el gobierno público se replican analógicamente en el gobierno de la esfera privada e incluso personal, calificándolas así de manera política. ¿De qué manera Aristóteles compara el modo de gobierno familiar con el político? Él considera conveniente adjetivar las diferentes realidades relativas familiares conforme a alguna modalidad política: a la relación heril, la califica de despótica; a la paterna, de monárquica o regia; y a la conyugal de política o aristocrática. De este modo, si en la esfera privada lo adecuado es que haya al mismo tiempo mando despótico, monárquico, y político-aristocrático, conforme a los distintos términos relativos gobernados -esclavo, hijo o mujer-, en el ámbito público es una sola la forma de gobierno la que se adecua plenamente a la naturaleza humana: la político-aristocrática. (Por lo demás, hay que recordar que para Aristóteles la realización de esta forma política no es necesaria, sino algo más bien difícil de alcanzar, a causa de la madurez que se exige de parte de los miembros de la comunidad política). No cabe duda, entonces, que el punto de partida para efectuar analogías que ayuden a comprender la naturaleza social del hombre, es para el Estagirita el ámbito político. Y la operación inversa, a saber, calificar las relaciones políticas por alguna modalidad familiar, aunque no imposible, resulta para el filósofo griego menos apropiada y más bien ligada a la poesía ${ }^{31}$.

28 Cfr. Pol., I, 12, 1259a37-42; I, 3, 1253b11-20.

29 Pol. I, 12, 1259a40-41. La manera propiamente política de gobierno se condensa adecuadamente en esta fórmula de Pol., III, 1283b40-1284a2: "Ciudadano en general (polítes dè koinê) es el que participa (ho metéjon) del gobernar y del ser gobernado (toû árjein kaì árjesthaí); en cada régimen (kath' ekásten politeían) es distinto, pero en el mejor (pròs tèn arísten) es el que puede y elige obedecer y mandar con miras a una vida conforme a la virtud (ho dynámenos kaì proairoúmenos árjesthai kaì árjein pròs tòn kat' aretén)».

30 Cfr. nota n. 11.

31 En Pol., I, 2, 1252b17-27 y I, 12, 1259b10-17, citando a Homero y a Platón (quien también era deudor de Homero en este punto), Aristóteles explica de qué modo en Zeus su condición de «rey» (basileús) se explica por su condición de "padre» (patèr). Y en el siguiente texto de la Ética a Nicómaco se observan las dos direcciones argumentativas, a saber, de lo 
De esta forma se comprueba en Aristóteles una orientación a entender y vivir la realidad familiar como una realidad en cierta manera política. Pues sin esta orientación faltaría la base adecuada de una concepción y vivencia política auténtica y madura, esto es, que la comunidad política pueda verse compuesta por personas libres y racionales, como quiere Arendt. Pero a diferencia de Arendt, que sostiene que la libertad y racionalidad de las personas se forma exclusivamente en el ámbito de la polis, para Aristóteles ellas ya comienzan a formarse en instancias sociales anteriores —familiares, barriales, aldeanas, etc.-—:

«Como toda casa es una parte de la ciudad (...), es necesario educar a los hijos y a las mujeres con vistas al régimen de gobierno, si es que precisamente tiene alguna importancia para que la ciudad sea perfecta que sean perfectos los hijos y las mujeres. Y necesariamente tiene importancia, pues las mujeres son la mitad de la población libre, y de los niños salen los miembros de la comunidad política» ${ }^{32}$.

En este sentido, la dificultad que presenta la interpretación de Arendt es que, al concebir, como propia de Aristóteles, una separación tan tajante entre lo público y lo privado, lo que pretende a fin de cuentas es sostener que en el Estagirita la realidad familiar está completamente ausente de la concepción y vivencia política; y con ello pasa por alto el innegable potencial político que Aristóteles imprime en todo lo doméstico. De esta manera, conforme a la interpretación de Arendt, la política aristotélica realmente se halla como en suspenso social, corriendo serio riesgo de ser una fatua utopía republicana. A decir verdad, en Aristóteles no es únicamente natural a la condición humana su politicidad, sino antes que nada su sociabilidad. Y, según lo visto, esta dimensión presenta tres facetas: despotismo, civismo y realeza. Efectivamente, al hablar sobre la naturaleza de la familia, Aristóteles expone la condición humana natural del despotismo, el civismo y la realeza. Sin espacio aquí para extendernos al respecto, apuntemos simplemente que todo hombre que aspira a la perfección humana, antes de llegar a ser plenamente libre en la perfección de la vida política o cívica, debe ejercitar adecuadamente el despotismo ${ }^{33}$, el civismo y la realeza en el seno familiar o, si se quiere, social.

político a lo familiar, y viceversa; salvo que en la dirección de lo familiar a lo político se vuelve a citar a Homero: «La comunidad del padre con los hijos tiene forma de realeza (basileías), puesto que el padre se ocupa de los hijos; de ahí que también Homero se dirija a Zeus como padre [Ilíada, I, lin. 544: patèr andrón te theôn], ya que la realeza pretende ser un gobierno paternal (patrikè arjè). En Persia, en cambio, el gobierno del padre es tiránico (tyranniké) y los padres tratan a sus hijos como esclavos». EN, VIII, 10, 1160b24-25.

32 Pol., I, 13, 1260b13-20.

33 Por lo demás, para el Nuevo Testamento también parece de algún modo natural la dimensión del dominio heril; al menos ello es así según el modo de expresión: «el Reino de los Cielos se parece a un propietario (patri familias; oikodespóte) que salió muy de madrugada a contratar obreros para trabajar en su viña» (Mt., 20, 1). Para la versión castellana, utilizo la versión de la Biblia titulada El Libro del Pueblo de Dios (trad. argentina), Libreria Editrice Vaticana, 1990, disponible en http://www.vatican.va/archive/ESL0506/_INDEX.HTM\#fonte; para la versión latina, la Nova Vulgata Bibliorum Sacrorum Editio (editio typica altera), Libreria 
Pasemos ahora a ver qué sucede con Tomás de Aquino y la analogía que él establece entre el dominio doméstico y el dominio político, intentando determinar si acaso invierte la postura aristotélica, reduciendo lo político a lo doméstico. En su exposición, Arendt arguye que «dominus» es el término latino de mayor riqueza y precisión para explicar lo que es el paterfamilias, esto es, el jefe de la comunidad familiar. Pero en este caso ella no cita a Tomás de Aquino, ni siquiera a algún otro autor medieval, sino a autores de la época romana, a los que Tomás no sigue en esta cuestión. Así, en la nota n.12 del cap. II del libro de Arendt (2003: 85), se lee: «dominus y paterfamilias fueron sinónimos, al igual que servus y familiaris: Dominum patrem familiae apellaverunt; servos... familiares (Séneca, Epístolas, 47.12)». A esto Arendt añade que «la antigua libertad romana del ciudadano desapareció cuando los emperadores romanos adoptaron el título de dominus, "ce nom, qu'Auguste et que Tibére encore, repoussaient comme une malédiction et une injure"» (H. Wallon, Histoire de l'esclavage dans l'antiquüé, 1847, vol. III, pág. 21)». Antes que nada, hay que hacer notar que, a partir de esta cita de Wallon, el rechazo de Augusto o Tiberio a ser llamado dominus no parece haberse debido a un intento de evitar que se los asocie a un déspota familiar sino más bien a un ser divino. En cualquier caso, tanto el dominus-paterfamilias cuanto el dominus-imperator de los romanos no sirven para comprender — al menos no de forma directa, clara y manifiesta- el pensamiento de Tomás de Aquino.

De hecho, la razón de «paternidad» y la de «dominio» para el Aquinate son diferentes ${ }^{34}$. Si la razón de «paternidad» consiste en la de dar el ser a alguien, engendrándolo, la razón de «dominio» consiste en la de poder gobernar a alguien $^{35}$. Así y todo, Arendt igualmente se empeña en sostener que hay un dominus-paterfamilias, el cual, mientras que en Aristóteles no corresponde aplicar

Editrice Vaticana, 1979, disponible en http://www.vatican.va/archive/bible/nova_vulgata/documents/nova-vulgata_index_lt.html; para la versión griega, el Novum Testamentum Graece, Nestle-Aland, 1979, 26th edition, Deutsche Bibelgesellschaft, Stuttgart, disponible en http:// www.greekbible.com/.

34 «Secundo [sacerdos] Deum implorat ad laudem suscipiendum, ostendens laudis debitum, dicens: "Vere dignum", ratione dominio, unde subdit: "Domine sancte"; "justum" ratione paternitatis, unde subdit: "Pater omnipotens"». Thomas de Aouino (1947: 355), Super IV Sent., d. 8, expos. textus.

${ }_{35}$ En un discurso cuyo sujeto de referencia es Dios, lo cual ciertamente no invalida la aplicación extensiva por analogía a la realidad humana, el Aquinate expresa lo siguiente acerca de la esencia de paternidad: «Deus per hoc quod dat esse creaturae, dicitur creator, et per hoc quod dat esse Filio, dicitur pater» (Thomas de Aouino (1929: 254), Super I Sent., d. 9, expos. textus); y sobre la esencia de dominio, dice esto otro, lo cual corresponde no sólo a Dios Padre sino también a Dios Hijo: «si pater dicitur dominus omnium, ratione creationis, similiter et filius, per quem omnia producuntur in esse, dominus est. (...) Secundo quia filius est patris sapientia, qua omnia gubernat. (...) Si ergo pater dicitur dominus ratione gubernationis (...), et filio competit dominium. Item pater est dominus, inquantum ad ipsum omnia ordinantur, sicut ad primum principium, et finem omnium; similiter et filius, qui est Dei sapientia, praecedens omnia, dominus est. (...) Prov. XVI, v. 4: universa propter semetipsum operatus est dominus». Super Heb., cap. 1, lect. 1 [fragmentos de la reportatio que es distinta 
al que gobierna la polis, en Tomás de Aquino pasa efectivamente a corresponder. De esta manera, según esta intérprete, en la concepción del Aquinate la comunidad política consistiría en una gran casa o familia, gobernada por un dominus llamado rex o imperator. $\mathrm{O}$, más bien —la misma Arendt matiza-, tal como de hecho ocurrió en la Edad Media, la comunidad política no estaría destinada a convertirse en una gran familia sino en un conglomerado de familias, contando con un dominus como cabeza principal; no, por cierto, un señor absoluto, sino un señor feudal al modo de un primus inter pares. Desde luego, esta observación de tipo histórica no modificaría en esencia la concepción tomista, haciendo que la comunidad deje ser familiar y pase a ser política ${ }^{36}$. De ser las cosas tal como interpreta Arendt, la incompatibilidad con Aristóteles salta a la vista, pues el griego no acepta que el modo óptimo de gobernar una polis sea el de un monarca, déspota o dominus (tomados todos estos términos como sinónimos), al haber rechazado expresamente la conveniencia de concebir la polis como una gran familia ${ }^{37}$. En consecuencia, si se sigue a Arendt, la oposición entre Tomás y Aristóteles no puede ser más evidente.

Puede que con su interpretación de Aristóteles, Arendt haya hecho algún aporte a la rehabilitación del republicanismo; pero en lo que hace a su interpretación de Tomás de Aquino, sus prejuicios no la benefician. Partiendo de esa supuesta concepción y/o realidad histórica medieval de la figura de un dominus despótico que se expande por todo tipo de dominación feudal, Arendt piensa que nadie mejor que el Aquinate - figura intelectual prominente del esplendor medieval - representa esa forma de pensar. Se ha equivocado de autor. Esa forma de pensar, que podría ser imputada a las preferencias de un Carl Schmitt o un Otto Brunner ${ }^{38}$, incluso tal vez tendría dificultades de ser aplicada a algún

a la vulgata: ver http://www.corpusthomisticum.org/che00n.html y http://www.corpusthomisticum.org/che01.html].

36 Cfr. ARENDT (2003: 85, nota n. 14).

37 Cfr. Pol., I, 1, 1252a12.

38 En su Verfassungslehre, Schmitt aduce que, a diferencia de las formas típicamente modernas de fundamentar la monarquía, cualquier modo de hacerlo antes del siglo xvIII conllevaba negarle «un principio político formal en su peculiaridad» (Schmitt, 1982: 277). Como «fundamentaciones principales de la Monarquía» realizadas según la mentalidad preracionalista, este autor señala la religiosa (el monarca es divino) y la paterna (el monarca es un padre). Según esta última, «la autoridad y poder del padre en la familia, la patria potestas, se traslada al Estado, que es así concebido como una familia agrandada» (Schmitt, 1982: 275; cfr. 274-277). Aunque Schmitt no cite a Tomás de Aquino, es notable de qué modo el diagnóstico de Arendt acerca de la concepción tomista supuestamente apolítica, coincide con este de Schmitt acerca de esas fundamentaciones de tipo medieval. Ello no es casual; incluso aunque de esa coincidencia resulte una valoración diametralmente opuesta en cada caso.

Por su parte, Brunner también fue influido por el pensamiento de Schmitt, pero recibiendo en su caso de buena gana esta influencia. Brunner (2010) sostiene que en la Edad Media la vida social prácticamente en su totalidad estuvo signada por una especie de pan-economización (en el sentido antiguo y medieval del término "economía»), ya que la vida de las fincas - casas grandes de campo- determinaban el modo de vida en su totalidad. Brunner está registrando la forma de vida medieval, no alguna teoría medieval que haya abogado por 
representante del agustinismo político medieval; con mayor razón, entonces, al aristotélico medieval por antonomasia que fue Tomás de Aquino ${ }^{39}$.

La interpretación de Arendt no se sostiene siquiera empezando por una exégesis de tipo lingüística, como estamos haciendo ver. Al respecto, y para concluir este punto, me gustaría destacar la claridad con la que, en un texto raramente citado, Tomás establece la distinción mutua entre todos estos términos: dominus, paterfamilias, rex y tyrannus. Se trata del sermón Ecce rex tuus ${ }^{40}$. Allí, en lo que atañe a la distinción de dominus y rex, se lee: «el rey manda por la autoridad de dominio (auctoritate dominii), pero no cualquiera que tiene autoridad de dominio se dice rey ${ }^{41}$. Es decir, el término dominus es genérico respecto del específico rex. Y en lo que hace a la distinción entre el paterfamilias y el rex, leemos: "“rey” conlleva amplitud de jurisdicción. El paterfamilias tiene plenitud de potestad (potestatis) en su casa, sin embargo no se dice "rey". De modo similar, quien tiene un pequeño poblado (villa), no por ello se dice "rey", sino que se dice "rey" quien tiene dominio (dominium) sobre muchas tierras y sobre una ciudad grande (civitatem magnam) ${ }^{42}$. Lo primero a observar es la sinonimia entre potestas y dominium. Ello nos permite retomar lo dicho con motivo de la distinción anterior entre dominus y rex, y observar que también paterfamilias es una especie de dominus.

Ahora bien, respecto de la razón de la diferencia de dominio que hay entre el paterfamilias y el rex, ese sermón señala el tamaño de aquello sobre lo que se ejerce potestad o dominio: una casa, una villa, o una gran ciudad. De este modo, el gobierno de una casa y el de un reino parecerían ser de la misma especie, diferenciándose únicamente en el tamaño, tal como interpretara Arendt. ¿Es esto realmente así? Veamos por qué no, dejando entrever que las diversas formas de gobierno domésticas no pueden proyectarse simétricamente al ámbito del reino (civitas magna). En primer lugar, está la diferencia que introduce en la realidad del dominio el concepto de tirano: «es preciso que el rey tenga equidad (aequitatem), ya que de otro modo sería un tirano, porque el tirano convierte

ella; pero su propio registro supone una teoría, a saber, la de que la vida económico-rural fue el principal elemento configurador de la sociedad medieval. Ante la paulatina pérdida de ese modus vivendi económico pre-político, noble y señorial, que se iría perdiendo con el correr de los siglos, dando lugar a los Estados nacionales modernos, comercializados y racionalizados constitucionalmente, la exposición de Brunner denota una clara nostalgia.

Con toda verosimilitud, es a partir de este tipo de autores, aunque no los cite, que Arendt pudo haberse formado la representación de una asociación medieval de equivalencia específica entre dominio familiar y dominio político-monárquico, para achacársela luego a Tomás de Aquino.

39 Como mostraré en otro lugar, incluso en el De regno, su texto aparentemente menos republicano y más teocrático, el Aquinate demuestra ser claramente aristotélico —no importa, desde luego, que ese aristotelismo se encuentre allí conjugado con la filosofía del $D e$ civitate Dei — que no es lo mismo que el llamado «agustinismo político».

40 Thomas de Aquino (1946: pars 2).

41 Ibíd.

42 Ibid. 
todas las cosas que se encuentran en el reino para su propio provecho; en cambio el rey ordena su reino al bien común ${ }^{43}$. De esta forma, queda descartada la suposición de Arendt y Habermas de que gobernar de modo monárquico implica forzosamente gobernar de modo tiránico. Según el Aquinate, sólo puede decírsele con propiedad «rey» a quien gobierna con justicia (aequitas justitiae); a quien lo hace con injusticia, hay que llamarlo «tirano». Esta distinción es fundamental para hacer notar a continuación que el hecho de que haya verdadera polis (civitas o república), para Tomás de Aquino no está ligado al hecho de una forma específica de gobierno, sino a que en la comunidad reine la justicia y brille la virtud de sus ciudadanos. De este modo, para que haya vida política o república, da igual si la polis es gobernada por un príncipe, por un consejo de magistrados, o de la forma que sea. Es fácil percatarse entonces de que un auténtico rey no puede mandar de manera despótica sin que automáticamente pase a ser un tirano.

A partir de esta primera cuestión se entiende la segunda. Del hecho de que Tomás aduzca una mera cuestión cuantitativa para diferenciar un paterfamilias de un rex, no implica que necesariamente piense que esa es la única razón de la diferencia. Habiendo quedado claro ya con Aristóteles la necesidad de que existan diversas formas de gobierno en la casa, a saber, una despótica-heril, otra monárquica-paterna, y otra político-aristocrática-conyugal, Tomás tiene claro que estas formas no pueden proyectarse simétricamente al ámbito del reino (civitas magna). En todo caso, habrá que ver cuáles son las circunstancias sociales para aplicar un tipo u otro de dominio. Desde luego, si el reino tiene siervos, y no hay más remedio que los tenga, a ese respecto corresponderá un gobierno despótico; y si tiene menores de edad o gente inmadura, a ese respecto corresponderá un gobierno monárquico. Lo deseable, por supuesto, es que en el reino predomine un gobierno de tipo político-aristocrático. Ahora bien, una polis absolutamente político-aristocrática, donde todos sus ciudadanos se conducen adecuadamente para expresar sus ideas y son libres, es, si no una utopía, un ideal muy difícil de alcanzar; y algo que, desde luego, Tomás de Aquino estaba muy lejos de poder haber visto por el tiempo histórico que le tocó vivir ${ }^{44}$. En cualquier caso, no porque en un reino haya siervos, y por tanto despotismo, necesariamente habrá tiranía: el rey puede ser justo y equitativo aun existiendo cierta servidumbre, y de ese modo se daría un auténtico reino. Ahora bien, donde hay justicia, la libertad está viva y florece la virtud. Y donde los ciudadanos son virtuosos, la sociedad tiende a madurar y ser libre, penetrando su autarquía en todos y cada uno de los ciudadanos; en una palabra, la esclavitud tiende a desaparecer. ¿Qué se deduce de esto? Que, no porque haya un rey a la cabeza, los ciudadanos no hayan de poder gobernarse de alguna manera a sí mismos, esto es, no porque haya monarquía habrá de suprimirse

43 Ibid.

44 «Luego del surgimiento de la vida urbana en la alta Edad Media, entre un 70\% y un 90\% de la población seguía siendo campesina, si hacemos caso omiso de unas pocas regiones»(Brunner, 2010: 122). 
forzosamente la aristocracia y la democracia de la sociedad; pudiendo, a su vez, ser suprimidos el despotismo y la esclavitud. En cambio, en el caso de la familia, no puede decirse de todos sus miembros que, además de ser gobernados monárquicamente por el paterfamilias, puedan a su vez gozar de alguna forma de autogobierno, deliberación y diálogo; esto sólo puede decirse de la mujer, pero no de los siervos ni de los hijos. A los siervos de la casa sólo les convendrá una monarquía de tipo despótica; y a los hijos una monarquía de tipo paterna. Por consiguiente, la extensión simétrica —según una misma especie- del gobierno de la familia al del reino, no es algo que Tomás de Aquino haya tenido intención de formular.

Una vez efectivamente registrada la distinción específica entre el dominio familiar y el dominio político regio que se deduce de la enseñanza del Aquinate, puede entenderse correctamente la semejanza por analogía que existe entre ambos. Al respecto, mientras Arendt y Habermas pretenden que Tomás de Aquino extiende esa analogía desde la familia a la comunidad política, en realidad, también en Tomás (como antes en Aristóteles) el sentido principal es exactamente el inverso: de la realidad política a la familiar. En este sentido, aunque naturalmente el Estado deriva de la familia y las constituciones políticas de las estructuras familiares, sin embargo, a la hora de conceptualizar esa génesis real, la dirección asignada es principalmente la inversa: las estructuras políticas se aplican por analogía a las familiares. Y secundariamente, sí, lo familiar puede aplicarse a lo político ${ }^{45}$.

Habiendo abordado los tipos o formas categoriales del dominio, y su complejidad analógica, es preciso abordar ahora la manera o modo trascendental de dominar. En relación a ello tiene particular relieve la concepción aristotélica de la relación del cabeza de familia con su mujer. En efecto, al hablar de dicha relación, Aristóteles emplea el término griego que más específicamente corresponde al «dominus» latino: «kýrios».

\section{El DOMINIO COMO MANERA DE EJERCER EL PODER: EL KÝRIOS, POSEEDOR DE SUFICIENTE Y JUSTA DÝNAMIS}

La diferencia establecida por Aristóteles en el seno de la familia entre autoridad despótica, por un lado, y autoridad marital y paterna por otro, resulta esencial para entender la doble cara natural del dominio. Si en Tomás de Aquino esta filosofía todavía sigue en pie, luego de él parece haberse ido diluyendo o desfigurando. En Domingo de Soto, por ejemplo, el dominio despótico pierde

45 "Quien rige una comunidad perfecta, esto es, una ciudad o una provincia, se llama por antonomasia "rey"; en cambio, el que rige una casa, no se dice "rey" sino "paterfamilias", no obstante tenga cierto parecido con el rey, por lo que a veces los reyes se denominan "padres de los pueblos"». Thomas de Aouino (1979: 451), De Regno, I, 1, lin. 167-172. 
su carácter natural y, por otra parte, ya no se puede decir que el varón sea propiamente señor de la mujer, ni el padre de los hijos sea señor de estos ${ }^{46}$.

A fin de entender la complejidad natural de la polis, en el libro III de la Política (4, 1277a5-10) Aristóteles la compara con diferentes realidades compuestas, naturales o artificiales, entre las cuales se menciona la casa (oikía) como distinta de la propiedad (ktêsis). Mientras la ktêsis (propiedad, tierra, finca, granja) se compone de amo (despótes) y esclavo (doúlos), la oikía se compone de marido (anér) y mujer (guné) ${ }^{47}$. Es decir, para Aristóteles no hay todavía propiamente casa o familia si no hay autoridad marital; este es su elemento especificante, y en cuyo caso el único término relativo posible del señor que gobierna es la mujer.

Y si la mujer da lugar a una relación política en el seno familiar, se debe a la presencia en ella de facultad deliberativa: tò bouleutikón ${ }^{48}$; algo de lo que el esclavo carece, y en lo que el niño todavía no ha madurado ${ }^{49}$. Tal como se expone en la Ética a Nicómaco, libro III, cap. 3 (1113a10-11), lo deliberativo es elemento esencial de la proaíresis: proaíresis àn eín bouletikè órexis tôn eph' emîn, «la elección es un deseo deliberado de lo que depende de nosotros». Ahora bien, la proaíresis es lo que define al hombre ${ }^{50}$. Es decir, es el hombre mismo en su estado perfecto, esto es, de libertad. De esta manera, si la mujer cuenta

46 Cfr. Domingo de Soto (1995: n. 24-25 y n. 38). Respecto de lo primero: «La servidumbre no es natural según el primer modo [a saber, según la "primera intención de la naturaleza»], porque la naturaleza pretende la libertad; pero accidentalmente es natural, esto es, ha sido dada como pena por razón del pecado. Por lo cual en la guerra la pena del enemigo es que sea siervo» (ibíd.: n. 25, p. 51). Respecto de lo segundo: "Como ha quedado dicho, se llama propiamente señor al que usa del siervo para utilidad no suya, es decir, del siervo, sino del mismo señor; ahora bien, el hombre no debe usar para su propia utilidad de la esposa y de los hijos, sino para el bien de los mismos; por consiguiente. Por lo cual Aristóteles, en el libro I de la Política, dice que hay tres partes en la casa: Una dominical, otra paterna, otra conyugal; y declara esto porque manda sobre la esposa y los hijos no como a siervos sino como a libres, rigiéndolos y gobernándolos. Y todavía establece diferencia entre la esposa y los hijos, porque manda sobre la esposa con principado político, esto es, a la manera como manda aquél que por el solo consentimiento del pueblo y en precario manda sobre el pueblo; pero el padre manda sobre los hijos con principado regio a la manera como el rey manda sobre el reino con potestad propia y no en precario, como sí tuviera mayor potestad sobre los hijos que sobre la esposa. Pero, ni una ni otra es dominical» (ibíd.: n. 38, p. 185). La misma doctrina se expone también en Domingo de Soto (1559: 202), De iustitia et iure, IV, q.1, a.1: «ius in liberos non proprie dicitur dominium, sed in servos».

47 En Pol., I, 2, 1252b11-16, al caracterizar inicialmente la conformación económica (de la casa), Aristóteles incluye todo: esclavos, animales domésticos y bienes también. Pues se refiere a todos los elementos que contribuyen a la unidad familiar como «la comunidad constituida naturalmente para la vida de cada día».

48 Pol., I, 13, 1260a13-14.

49 «Las mujeres son la mitad de la población libre, y de los niños salen los miembros de la comunidad política». Pol., I, 13, 1260b18-21.

50 "La elección (proaíresis) es o inteligencia deseosa (orektikòs noûs) o deseo inteligente (órexis dianoetiké), y tal principio es el hombre (kaì e toiaúte arjè ánthropos)». EN, VI, 2, 1139b5-6; cfr. EN, III, 3; Pol., I, 13, 1260a9-14. 
con facultad deliberativa, quiere decir que es plenamente humana, igual que el varón. Esto se confirma por la siguiente conclusión expresada en el último cap. del libro I de la Política:

«Así pues, está claro que el cuidado de la administración de la casa debe atender más a los hombres que a la posesión de cosas inanimadas (é spoudè tês oikonomías perì toùs anthrópous è perì tèn tôn apsújon ktêsin), y a las virtudes de aquéllos más que a la posesión de la llamada riqueza, y más a las de los libres que a las de los esclavos ${ }^{51}$.

La mujer (guné) o ser femenino (thêlus) es algo tan humano (ánthropos) como el marido (anér) o ser masculino (ársen). Entonces, ¿dónde radica la diferencia? Lo que para Aristóteles la mujer no tiene, es autoridad. En efecto, su facultad de deliberar (tò bouleutikón) es ákyron, es decir, carente de autoridad o señorío ${ }^{52}$. En otros términos, la mujer es un ser libre pero necesitada de autoridad, ya que en sí misma no la tiene. No es kyría (domina), como el varón cabeza de familia es kýrios (dominus). ¿Por qué no lo es? Porque le falta poder (dýnamis). Es capaz de deliberar — cuenta con proaíresis-, y por tanto tiene voluntad libre (boúlesis), pero no tiene dýnamis; al menos no suficiente como para ser señora, esto es, autoridad. En efecto, la caracterización aristotélica más acabada del kýrios es el de aquel que se distingue por detentar poder. Kýrios y dýnamis son términos intrínsecamente ligados. "Los dueños del poder» (hoi kýrioi tês dynámeos) son aquellos capaces de sustentar sólidamente el gobierno de otros (enkratôs ésjon tèn arjén ${ }^{53}$. El poder de la autoridad (kýrios) es algo objetivo — por ej., capacidad de persuasión, riqueza, fuerza militar, $k a-$ lokagathía, etc.- - y es algo intenso, fuerte o grande, a causa de lo cual el kýrios puede hacer lo que quiere respecto de los que se encuentran sujetos a ese poder.

Por tanto, cuando Aristóteles expresa en la Retórica ${ }^{54}$ que caben tantas formas de autoridad (kýriá) cuantas formas de gobierno (politeîai), no hay que pensar que con ello está equiparando ambos términos — kyría y politeía-, como si fueran sinónimos. Por el contrario, ambos términos se distinguen, y lo hacen en razón de que kýrios alude específicamente a una manera de detentar la autoridad por parte precisamente del árjon, es decir, del que rige según cada forma distinta de gobierno — democrática, oligárquica, aristocrática o monárquica- La manera de gobernar, aneja a una determinada forma, alude a una intensidad mayor o menor de su autoridad, de acuerdo al grado de poder que tenga; no a la forma de poder que detente. Así, si se gobierna para conseguir libertad —esto es, de forma democrática—; o se gobierna para conseguir riqueza —esto es, de forma oligárquica—; o si de acuerdo a las leyes y para ser mejores — esto es, de forma aristocrática—; o si para tener fuerza militar — esto

$51 \quad$ Pol., I, 13, 1259b1-19-20.

52 Pol., I, 13, 1260a13-14.

53 Pol., III, 13, 1284a39-41.

54 Cfr. Ret., I, 8,1365b27-1366a14. 
es, de forma tiránica— ${ }^{55}$, todavía restaría considerar con qué autoridad se lo hace. Al respecto, puede recordarse que el correlativo aristotélico de doúlos (esclavo o siervo) no es kýrios sino despótes ${ }^{56}$; el correlativo de kýrios en Pol., II, 9 es aphistaménos (rebelde). El despotismo es una forma predicamental de gobierno. El dominio, en cambio, parece aludir a un aspecto de carácter más bien trascendental, admitiendo diversos grados de intensidad en su ser.

No hay muchas evidencias textuales de lo que quiero hacer ver. Pero basta observar con atención las pocas que hay para detectar la dirección a la que necesariamente ellas conducen. En el intento de perseguir hermenéuticamente las notas distintivas del kýrios aristotélico es preciso reparar en Pol., II, 9. Si dijimos recién que el kýrios es el que detenta dýnamis, a partir del análisis de ese texto se podrá añadir que el modo adecuado de detentar poder es haciéndolo según término medio entre el rigor y la laxitud. Y el término medio virtuoso entre lo recio y lo blando, no tiene en sí mismo límite: es ilimitado, como el ser trascendental. Analizando allí la situación de los ilotas en Esparta, Aristóteles dice que «se han rebelado muchas veces (epétheto pollákis)» contra los laconios $\mathrm{y}$ «pasan la vida al acecho de los infortunios de estos» (Pol., II, 9, 1269a37-38). Los ilotas eran una especie de siervos campesinos, que habiendo sido habitantes de las tierras de Lacedemonia desde antes de la inmigración doria, habían sido subyugados por estos tras su ocupación. Los ilotas eran, por tanto, gente sometida, pero no estrictamente esclavos (doulô̂). De hecho, Aristóteles se refiere a ellos como «rebeldes» (aphistaménois: Pol., II, 9, 1269b2), y a los ciudadanos que vivían temiendo por su levantamiento, los llama «señores» (kýrioi: cfr. Pol., II, 9, 1269b11). Así, el término kýrios se muestra en relación a mandar algo que no parece fácil de someter, tal como es el caso de un siervo rebelde. Y ¿por qué el ilota es característicamente rebelde? Pues al no ser un esclavo, ni tampoco un ciudadano libre, es alguien cuya ubicación o función social no se encuentra bien definida. Se trataba de una suerte de paria cuyo origen se remontaba a la invasión, conquista y sojuzgamiento por parte de ciertos agresores. Pero más allá de la cuestión histórica, en la que ciertamente también está en juego el bajo nivel de civilización de los mismos conquistadores ${ }^{57}$, lo que interesa en este momento es atender a las razones del uso aristotélico de kýrios en este contexto, a fin de aclarar el camino para la concepción propiamente tomística del dominus. En este sentido, pues, no importa que los primeros conquistadores no hayan sido señores (kýrioi), si los actuales dominadores lo son. Aristóteles sostiene que es difícil dar con la manera adecuada de establecer la relación de señorío con un rebelde como el ilota: «parece incluso que, aun sin otra dificultad más que la del mero cuidado sobre otro (tês epimeleías), es difícil [descubrir] cuál tenga que ser (tína dê̂) respecto de los mismos (pròs autoùs)

55 Cfr. Ret., I, 8, 1366a4-7; Pol., IV, 3, 1290a5-10 y Pol., IV, 4, 1290a30-34.

56 Cfr., por ej., Pol., I, 3, 1253b15.

57 Cfr. Pavel (1983: 45). 
[i.e., respecto de los sometidos al modo ilota] la manera (trópon) de tratarlos (homilêsai) ${ }^{58}$.

En síntesis, «señor» (kýrios) es alguien que tiene mando sobre un súbdito de complicado sometimiento. Por eso, en su singularidad terminológica, parece apuntar más a la manera de tratarlo (homilêsai trópon), a saber, si de manera recia o blanda, que al tipo, especie o forma de hacerlo (trópos, también ${ }^{59}$ ), a saber, si despótico, aristocrático o monárquico. En efecto, al momento de determinar Aristóteles la clase de mando adecuada que le corresponde a un kýrios respecto de un ilota, lo hace de forma más bien negativa: ejercer señorío en este caso es saber evitar los extremos de la blandura o la dureza. En efecto, «si [a esos súbditos al modo ilota] se les da libertad (aniémenoi), se sublevan (ubrízousi) y se estiman dignos de los mismos derechos que los señores (tô̂s kýríois), y si llevan una vida miserable, conspiran y odian» (Pol., II, 9, 1269b9-11). Cerrando la secuencia argumentativa, y como poniendo límite a la condición histórica que se cierne sobre el concepto en discusión, el Estagirita termina estableciendo que la mejor forma de ser señor, esto es, de tratar a un súbdito, no es la que se emplea para con un ilota: «Es evidente que no han encontrado la mejor manera (tòn béltiston trópon) [de ser señor] aquellos para quienes la misma (toûto) se corresponde con el sistema ilota (sumbaínei perì tèn eiloteían)» (Pol., II, 9, 1269b11-12).

No es de sorprender que, aun habiendo partido el razonamiento de Aristóteles de circunstancias históricas tan desfavorables como para establecer en qué consiste el auténtico señorío, algo eternamente válido haya quedado de él. Lo que, en pocas palabras, queda, es que dominar - tener autoridad-es saber provocar cohesión en la gente gobernada. De este modo, también el concepto de «rebelde» parece trascender el plano histórico y ser aplicado al súbdito en tanto una modalidad más trascendental que categorial. Es decir, mientras se puede ser más o menos rebelde, o más o menos obediente, y, en este caso, ser mejor o peor súbdito, no se puede —en tanto que ser categorial— ser más o menos esclavo, ciudadano o extranjero: el hecho de ser de tal o cual tipo, implica serlo o no serlo en absoluto. En este sentido, el mismo esclavo de la familia, la mujer o el hijo también podrían convertirse en rebeldes si el déspota, el marido o el padre de la casa no saben ser buen señor, es decir, tratar a sus súbditos según el justo medio entre la rudeza y la laxitud.

Que esta doctrina ha llegado hasta el Aquinate esencialmente sin alteración, se demuestra por la lectura de una sola frase suya. Comentando al Ps.-Dionisio, Tomás de Aquino ha sintetizado la doctrina del dominio con la siguiente fórmula: potestas continendi et coercendi subditos (In de div. nom., cap. 12). Dominar consiste precisamente en esa capacidad o habilidad para contener y refrenar el desorden de los que están debajo, promoviendo a su vez el poder

58 Pol., II, 9, 1269b7-8. La trad. castellana de este pasaje por parte de M. García Valdés, en Aristóteles (1988), no me parece del todo clara: «Parece incluso que, sin otra dificultad, es arduo ya el tener que ocuparse de la manera como hay que tratar a los sometidos».

59 Cfr. nota n. 29. 
que les es propio. En este sentido, aun en el caso del trato con los siervos, el señorío lleva inherente una tendencia natural a tratar a los súbditos más como personas que como cosas ${ }^{60}$.

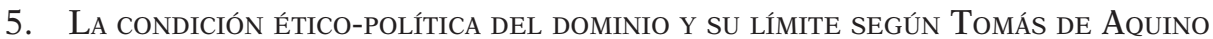

Según Tomás hay tres niveles de perfección humana susceptibles de ser alcanzados: el social, que es de un carácter ético más bien espontáneo, el político, que es de un carácter ético-jurídico más estructurado ${ }^{61}$, y el suprapolítico, que es de carácter contemplativo ${ }^{62}$. A juicio de Arendt, la teoría tomística del dominio transferiría todo el poder del civis, que se encuentra en el segundo nivel, es decir, el nivel político, al primero, es decir, el nivel social, donde según ella se encuentra el dominus tomístico. De esta forma, el Aquinate haría desaparecer de la vida humana las relaciones propiamente cívicas en favor de unas relaciones de tipo doméstico-señorial. Aquí se encierra una trampa lingüística que es preciso aclarar a la luz de lo visto.

En primer lugar, cuando Arendt expresa «dominus», en realidad se está refiriendo al señor en relación a sus siervos, es decir, al despota o tyrannus. Si bien es textualmente evidente que Tomás también utiliza el término dominus en relación al servus, la relación heril no es la única ni la principal relación de dominio existente para él. En efecto, para Tomás, el nivel en el que el dominus se ubica de manera prioritaria, es precisamente el nivel político ${ }^{63}$. Pues dominio equivale a libertad perfecta, no imperfecta. Siguiendo a Aristóteles, en Tomás lo «señorial» (lo propio de la relación de dominium o dominatio) no es expresión invariable de lo «despótico» (despotiké), sino principalmente de lo «libre» (lo «electivo»: bouletòn), que en el caso del hombre está determinado por lo «deliberativo» (proairetòn) ${ }^{64}$ y lo «posible» (dynatón $)^{65}$.

En segundo lugar, y para concluir, si efectivamente, tal como detecta Arendt, existe en Tomás de Aquino una orientación a buscar la perfección humana última fuera de la política, esta perfección no ocurre, como piensa ella, en dirección a lo individual o social en tanto que "ámbito privado», sino en tanto que realidad eminentemente "personal». Esto consiste en lo "contemplativo», es decir, en el ejercicio propio de la mente. Aunque ello, según advertimos, ya

60 En otro lugar me ocuparé de las implicancias trascendentales o metafísicas presentes en esta definición tomística de dominio.

61 La necesidad de virtud (areté) y justicia (dikaiosýne) para que haya polis, esto es, comunidad política perfecta, está expresado por Aristóteles, por ej., en Pol., I, 2, 1252b29-39 y en Pol., III, 9, 1280a5-13.

62 Cfr., por ej., Thomas de Aouino (1979: 467), De regno, II, 4, lin. 1-14.

63 Cfr. nota n. 13.

64 Cfr., por ej., EN, III, 3, 1113a3-5.

65 Cfr., por ej., EN, III, 3, 1112b25-26. 
esté anunciado de alguna forma por Aristóteles ${ }^{66}$, sin embargo, en el Estagirita la amenaza de totalitarismo político no deja de estar al acecho ${ }^{67}$. Por su parte, para Tomás, el hombre que vive a nivel político no se realiza plenamente a no ser que al mismo tiempo viva en un nivel más alto de perfección, suprapolítico. De esta manera, si el dominus es la última y más acabada figura de la causalidad humana, sin embargo él está llamado a convertirse en algo que trasciende la posibilidad de ser el causante único de su propia acción; está llamado a ser contemplativus $^{68}$, es decir, alguien que vive de su theoricus siue speculatiuus intellectus $^{69}$. Vivir así es hacerse lo más parecido posible a Dios, esto es, entrar en el dominio de lo divino. Entrar en el dominio de lo divino no es abandonar el ámbito de la causalidad humana, pues no por entrar allí se deja de ser humano, pero ciertamente es conjugar dicha causalidad con un modo de obrar causal respecto del cual corresponden reflexiones que ya no son de carácter puramente humano, esto es, ético-político, aunque tampoco exclusivamente divino, sino más bien metafísico, o si se quiere, personal. Aquí también se observa un desfase entre la lectura tomasiana de Aristóteles y la interpretación de Arendt: la libertad quasi anárquica que Arendt pretende para el nivel político aristotélico, en realidad pertenece - pero no por defecto de ley, sino por exceso- a este nivel suprapolítico, donde más que la ley, reina el amor.

\section{BiBLIOGRAFÍA}

Arendt, H. (2003), La condición humana (trad. de R. Gil Novales), Paidós, Buenos - Barcelona - México. [The Human Condition, 1958].

Aristóteles $^{70}$ (1985), Ética a Nicómaco [EN], trad. y notas por J. Pallí Bonet, Gredos, Madrid. [Ethikà Nikomájeia, circa 335-322 a.C.]

Aristóteles (1988), Política [Pol.], introd., trad. y notas de M. García Valdés, Gredos, Madrid. [Politiká, circa 335-322 a.C.]

ArIstóteles (1999), Retórica [Ret.], introd., trad. y notas de Q. Racionero, Gredos, Madrid. [Politiká, circa 335-322 a.C.]

${ }_{66}$ Ver notas n. 18 y 27. La virtud cívica no sólo es para el Estagirita distinta a la virtud personal, sino inferior. Cfr., por ej., 1276b30-1277a5.

67 «Y puesto que hay un fin único para toda ciudad (...) tampoco debe pensarse que ningún ciudadano se pertenece a sí mismo, sino todos a la ciudad, pues cada ciudadano es una parte de la ciudad, y el cuidado de cada parte está orientado naturalmente al cuidado del todo. También en eso se podría alabar a los macedonios, pues dedican la mayor atención a los niños y hacen de ella asunto de interés público». Pol., VIII, 1, 1337a22-33.

68 «Homo, inquantum est contemplativus, est aliquid supra hominem: quia in intellectus simplici visione continuatur homo superioribus substantiis». THомAs DE Aquino (1933: 1179), Super III Sent., d. 35, q. 1, a. 2, qc. 2, ad 1.

${ }_{69}$ Thomas de Aquino (1992), Super Boet. De Trin., pars 3, q. 5, a.1.

70 En algunos casos he modificado las traducciones usadas para las obras de Aristóteles, atendiendo al texto griego de Bekker (1831), disponible en http://www.perseus.tufts.edu/hopper/collection?collection=Perseus:collection:Greco-Roman. 
Ps.-Aristóteles (1984), Económicos, introd., trad. y notas de M. García Valdés, Gredos, Madrid. [Oikonomiká, circa 325-275 a.C.] ${ }^{71}$

Aubert, J.-M. (1955), Le droit romain dans l'oeuvre de Saint Thomas, L.P.J. Vrin.

Bertelloni, Francisco (2009), «¿Qué significa «política» en Sth., q. 96, a. 4? Sobre la génesis semántica de un vocablo», en José Meirinhos - Olga Weijers (eds.), Florilegium Mediaevale. Études offertes à Jacqueline Hamesse à l'occasion de son éméritat, Fédération Internationale des Instituts d’Études Médiévales, Louvain-la-Neuve, 19-36.

Bertelloni, F. y CRESPO, R. (2013), «Nota sobre la naturaleza «política» de «lo económico» para Aristóteles», Philosophia, vol. 73, 103-110.

Brunner, O. (2010), «La "casa grande” y la "Oeconomica” de la vieja Europa», Prismas. Revista de historia intelectual, $\mathrm{n}^{\circ}$ 14, 117-136. ["Das "ganze Haus” und die alteuropeische "Ökonomik"», en ID., Neue Werke der Verfassungs- und Sozialgeschichte, 1968].

Domingo де Sото [Dominicus Soto] (1559), De iustitia et iure, Lugduni, apud Gulielmum Rovillium; disponible en http://reader.digitale-sammlungen.de/resolve/display/ bsb10148078.html

Domingo de Soto (1995), Relectio de dominio, en ID., Relecciones y opúsculos I (ed. bilingüe, trad. e introd. de J. Brufau Prats), San Esteban, Salamanca.

Habermas, J. ( $\left.{ }^{4} 1987\right)$, Teoría y praxis. Estudios de filosofía social (trad. de S. Mas Torres y C. Moya Espí), Tecnos, Madrid. [Theorie und Praxis, 1963].

López, T. (2008), "Propiedad y dominio en Francisco de Vitoria», en J. Cruz Cruz (ed.), Ley y dominio en Francisco de Vitoria, Eunsa, Pamplona, 71-91.

Oliva, P. (1983), Esparta y sus problemas sociales (trad. de M. Picazo), Akal, Madrid [Sparta and Her Social Problems, 1971].

Schmitт, C. (1982), Teoría de la Constitución (versión española de F. Ayala), Alianza, Madrid. [Verfassungslehre, 1928].

Tellkamp, J. A. (2009), «Ius est idem quod dominium: Conrado Summenhart, Francisco de Vitoria y la Conquista de América», Veritas, nº 54, 3, 34-51.

Thomas de Aquino (1888), Summa theologiae [S.th.], en Sancti Thomae Aquinatis Opera Omnia, t. 4 (I, qq. 1-49), Iussu Leonis XIII P. M. edita, cura et studio fratrum praedicatorum, typographia polyglotta s. c. de propaganda fide, Roma. [1266-68].

Thomas de Aouino (1889), Summa theologiae [S.th.], en Sancti Thomae Aquinatis Opera Omnia, t. 5 (I, qq. 50-119), Iussu Leonis XIII P. M. edita, cura et studio fratrum praedicatorum, typographia polyglotta s. c. de propaganda fide, Roma. [1266-68].

Thomas de Aouino (1918), Summa contra gentiles [C.G.], en Sancti Thomae Aquinatis Opera Omnia, t. 13 (libri I et II), Iussu Leonis XIII P. M. edita, cum commentariis Francisci de Sylvestris Ferrariensis, cura et studio fratrum praedicatorum, Typis Riccardi Garroni, Roma. [1259-65].

Thomas de Aouino (1929), Scriptum super libros Sententiarum magistri Petri Lombardi episcopi Parisiensis, t. 1 [Super I Sent.], ed. P. Mandonnet, P. Lethielleux, Paris. [1252-56].

Thomas de Aquino (1933), Scriptum super libros Sententiarum magistri Petri Lombardi episcopi Parisiensis, t. 3 [Super III Sent.], ed. M.F. Moos, P. Lethielleux, Paris. [1252$56]$.

Thomas de Aquino (1946), [Sermo] Ecce rex tuus, ed. de J. Leclercq, «Un sermon inédit de Saint Thomas sur la royauté du Christ», Revue thomiste, vol. 46, 152-166.

71 Todavía se duda si esta obra no es efectivamente del propio Aristóteles. De no serlo, debería atribuirse a algún discípulo directo suyo, como Teofrasto. Cfr. la introd. de García Valdés, 236. 
Thomas de Aouino (1947), Scriptum super libros Sententiarum magistri Petri Lombardi episcopi Parisiensis, t. 4 [Super IV Sent.], ed. M.F. Moos, P. Lethielleux, Paris. [1252$56]$.

Thomas de Aquino (1953), Super Epistolam ad Hebraeos lectura [Super Hebr.], en Sancti Thomae Aquinatis Super Epistolas S. Pauli lectura, t. 2, ed. R. Cai, Torino - Roma, Marietti, $8^{\mathrm{a}}$ ed., 335-506. [1265-68?].

Thomas de Aquino (1965a), Expositio Super Iob ad litteram [Super Iob], en Sancti Thomae de Aquino Opera Omnia, t. 26, vol. II, Iussu Leonis XIII P. M. edita, cura et studio fratrum praedicatorum, Commissio Leonina, Roma. [1261-65].

Thomas de Aquino (1965b), Quaestiones disputatae de potentia [Q. de pot.], ed. P.M. Pession, Marietti, Torino - Roma, 10 a ed. [1265-66].

Thomas de Aquino (1971), Sententia libri politicorum [In Pol.], en Sancti Thomae de Aquino Opera Omnia, t. XLVIII, vol. A, Iussu Leonis XIII P. M. edita, cura et studio fratrum praedicatorum, Commissio Leonina, Roma. [1269-72].

Thomas de Aquino (1979), De regno ad regem Cypri [De regno], en Sancti Thomae de Aquino Opera Omnia, t. 42, Iussu Leonis XIII P. M. edita, cura et studio fratrum praedicatorum, Editori di San Tommaso, Roma, 447-471. [Circa 1267].

Thomas de Aouino (1992), Super Boetium De Trinitate [Super Boet. De Trin.], en Sancti Thomae de Aquino Opera Omnia, t. 50, Iussu Leonis XIII P. M. edita, cura et studio fratrum praedicatorum, Commissio Leonina, Roma - L. P. J. Vrin, Paris, 1-230.

CONICET - UCA,

CONICET (Argentina)

SANTIAgo Argüello

yagoarg@yahoo.com.ar

[Artículo aprobado para publicación en noviembre de 2014] 